\title{
Development and Validation of a Stability-Indicating RP-HPLC Method for the Simultaneous Estimation of Guaifenesin and Dextromethorphan Impurities in Pharmaceutical Formulations
}

\author{
Thummala V. Raghava Raju, ${ }^{1,2}$ Noru Anil Kumar, ${ }^{1}$ Seshadri Raja Kumar, ${ }^{1}$ \\ Annarapu Malleswara Reddy, ${ }^{1}$ Nittala Someswara Rao, ${ }^{2}$ and Ivaturi Mrutyunjaya Rao ${ }^{2}$ \\ ${ }^{1}$ Analytical Research and Development, Integrated Product Development, Dr. Reddy's Laboratories Limited, Bachupally, \\ Hyderabad-500072, India \\ ${ }^{2}$ School of Chemistry, Andhra University, Visakhapatnam, Andhra Pradesh 530003, India \\ Correspondence should be addressed to Thummala V. Raghava Raju; raghavartv@drreddys.com
}

Received 8 June 2013; Revised 9 August 2013; Accepted 9 August 2013

Academic Editor: Osama Y. Aldirbashi

Copyright (C) 2013 Thummala V. Raghava Raju et al. This is an open access article distributed under the Creative Commons Attribution License, which permits unrestricted use, distribution, and reproduction in any medium, provided the original work is properly cited.

\begin{abstract}
A sensitive, stability-indicating gradient RP-HPLC method has been developed for the simultaneous estimation of impurities of Guaifenesin and Dextromethorphan in pharmaceutical formulations. Efficient chromatographic separation was achieved on a Sunfire C18, $250 \times 4.6 \mathrm{~mm}, 5 \mu \mathrm{m}$ column with mobile phase containing a gradient mixture of solvents A and B. The flow rate of the mobile phase was $0.8 \mathrm{~mL} \mathrm{~min}^{-1}$ with column temperature of $50^{\circ} \mathrm{C}$ and detection wavelength at $224 \mathrm{~nm}$. Regression analysis showed an $r$ value (correlation coefficient) greater than 0.999 for Guaifenesin, Dextromethorphan, and their impurities. Guaifenesin and Dextromethorphan formulation sample was subjected to the stress conditions of oxidative, acid, base, hydrolytic, thermal, and photolytic degradation. Guaifenesin was found stable and Dextromethorphan was found to degrade significantly in peroxide stress condition. The degradation products were well resolved from Guaifenesin, Dextromethorphan, and their impurities. The peak purity test results confirmed that the Guaifenesin and Dextromethorphan peak was homogenous and pure in all stress samples and the mass balance was found to be more than $98 \%$, thus proving the stability-indicating power of the method. The developed method was validated according to ICH guidelines with respect to specificity, linearity, limits of detection and quantification, accuracy, precision, and robustness.
\end{abstract}

\section{Introduction}

Guaifenesin (GN), (+)-3-(2-methoxyphenoxy)-propane-1,2diol, is a widely used expectorant, useful for the symptomatic relief of respiratory conditions. Its empirical formula is $\mathrm{C} 10 \mathrm{H} 14 \mathrm{O} 4$, which corresponds to a molecular weight of 198.21. It is a white or slightly gray crystalline substance with a slightly bitter aromatic taste. Its solid oral dosage form is available as extended release tablets for oral administration [1].

Dextromethorphan (DN) [2-4] is the dextrorotatory enantiomer of the methyl ether of levorphanol and stereoisomer of levomethorphan. DN is an antitussive (cough suppressant) drug and used for pain relief and psychological applications [5-7]. Its empirical formula is $\mathrm{C} 8 \mathrm{H} 25 \mathrm{NO}$, which corresponds to a molecular weight of 271.4. It is a white powder. The combination of GN and DN is used to treat cough and chest congestion caused by the common cold, infections, or allergies. The chemical structures of GN and DN are shown in Table 1.

Impurity profiling of active pharmaceutical ingredients (API) in both bulk material and finalized formulations is one of the most challenging tasks for pharmaceutical analytical chemists under industrial environment [8]. The presence of unwanted or in certain cases unknown chemicals, even in small amounts, may influence not only the therapeutic efficacy but also the safety of the pharmaceutical products [9]. For these reasons, all major international pharmacopoeias 
have established maximum allowed limits for related compounds for both bulk and formulated APIs. As per the requirements of various regulatory authorities, the impurity profile study of drug substances and drug products has to be carried out using a suitable analytical method in the final product $[10,11]$.

GN and DN are official in the United States pharmacopeia and European pharmacopeia, but its combination is not official in any of the pharmacopeias. In the literature survey, there were several LC assay methods that have been reported for the determination of GN and $\mathrm{DN}$ in pharmaceutical preparation either individually or in combination with other drugs [12-20] and in human plasma by LC-MS [21, 22]. Few methods were available for the determination of impurities individually for GN and DN [27-29].

There is no single method reported for the simultaneous determination of the impurities in pharmaceuticals formulations of GN and DN. It is felt to develop a stability-indicating method for simultaneous determination of GN and DN related impurities in pharmaceutical formulation.

Hence, an attempt has been made to develop an accurate, rapid, specific, and reproducible method for the determination of GN and DN impurities (Tables 2(a) and 2(b)) in pharmaceutical dosage forms along with method validation as per ICH norms [23, 24]. The stability tests were also performed on both drug substances and drug products as per ICH norms $[25,26]$.

\section{Experimental}

2.1. Chemicals and Reagents. GN $+\mathrm{DN}$ tablets were received from the formulation research and development laboratory of Dr. Reddy's Laboratories Ltd., IPDO, Hyderabad, India. GN API and impurities were procured from Synthochem Lab., India. DN API and impurities were procured from Wochardt Laboratories Ltd., India. Sodium dihydrogen phosphate monohydrate, 1-octane sulfonic acid sodium salt monohydrate, HPLC grade acetonitrile, methanol, and orthophosphoric acid were purchased from Merck, Germany, Regis Technologies Inc, USA, and highly pure water was prepared by using Millipore MilliQ plus purification system.

2.2. Equipment. The LC system used for method development and method validation was Waters with a diode array detector (model: 2998 detector and e2695 separation module). The output signal was monitored and processed using Waters Empower software. Weighing was performed with a Mettler XS 205 Dual Range (Mettler-Toledo GmbH, Greifensee, Switzerland). Photo stability studies were carried out in a photo stability chamber (SUN TEST XLS+, Atlas, USA). Thermal stability studies were performed in a dry air oven (Merck Pharmatech, Hyderabad, India).

2.3. Chromatographic Conditions. HPLC measurements were carried out using a reversed phase Sunfire, C18, $250 \times 4.6 \mathrm{~mm}$, $5 \mu \mathrm{m}$ particle size column (Waters India Pvt. Ltd.) operated at $50^{\circ} \mathrm{C}$ with gradient elution at $0.8 \mathrm{~mL} \mathrm{~min}^{-1}$ using a mobile phase buffer as a mixture of $0.01 \mathrm{M}$ sodium dihydrogen phosphate monohydrate and 0.0046 M 1-octane sulfonic acid sodium salt monohydrate of $\mathrm{pH} 3.0$ ( $\mathrm{pH}$ adjusted with diluted orthophosphoric acid), UV absorbance at $224 \mathrm{~nm}$, injection volume $20 \mu \mathrm{L}$. The mobile phase A consisted of $\mathrm{pH} 3.0$ buffer and acetonitrile $(90: 10 \mathrm{v} / \mathrm{v})$; mobile phase $\mathrm{B}$ consisted of $\mathrm{pH}$ 3.0 buffer, acetonitrile, and methanol $(10: 10: 80 \mathrm{v} / \mathrm{v} / \mathrm{v})$. The LC gradient program was set as and time ( $\mathrm{min}) / \%$ mobile phase B: $0.01 / 15,15 / 5,20 / 30,30 / 50,60 / 85,65 / 15$, and 75/15. Pressure Range was 1700 psi to 2200 psi. Mixture of water, acetonitrile, and methanol $(60: 20: 20 \mathrm{v} / \mathrm{v} / \mathrm{v})$ was used as diluent for sample preparation.

\subsection{Preparation of Standard Solution and System Suitability} Solution. We prepared individual stock solutions for GN, $\mathrm{DN}$, and their impurities (each $500 \mu \mathrm{g} / \mathrm{mL}$ ). Working solution was prepared from the above stock solutions for related substances determination $(48 \mu \mathrm{g} / \mathrm{mL}$ of $\mathrm{GN}$ and $2.4 \mu \mathrm{g} / \mathrm{mL}$ of $\mathrm{DN})$. A mixture of all impurities ( $48 \mu \mathrm{g} / \mathrm{mL}$ of $\mathrm{GN}$ impurities and $2.4 \mu \mathrm{g} / \mathrm{mL}$ of DN impurities) along with $\mathrm{GN}$ and $\mathrm{DN}$ $(24000 \mu \mathrm{g} / \mathrm{mL}$ of $\mathrm{GN}$ and $1200 \mu \mathrm{g} / \mathrm{mL}$ of $\mathrm{DN})$ was also prepared in diluent. Stock solutions were used for method development and method validation.

2.5. Preparation of Test Solution. Twenty tablets (1200 mg of $\mathrm{GN}+60 \mathrm{mg}$ of $\mathrm{DN}$ ) were weighed and the average weight was calculated. The tablets were crushed into fine powder, and powder equivalent to $6000 \mathrm{mg}$ of $\mathrm{GN}$ (or equivalent to $300 \mathrm{mg}$ of DN) was transferred into a $250 \mathrm{~mL}$ volumetric flask. Approximately $170 \mathrm{~mL}$ of diluent was added, shaked to disperse the material, and sonicated for 20 minutes with intermediate shaking. The solution was then diluted to $250 \mathrm{~mL}$ and centrifuged at $3000 \mathrm{rpm}$ for $10 \mathrm{~min}$. The supernatant $(24000 \mu \mathrm{g} / \mathrm{mL}$ of $\mathrm{GN}$ and $1200 \mu \mathrm{g} / \mathrm{mL}$ of DN) was collected and filtered through a $0.45 \mu \mathrm{m}$ pore size nylon 66-membrane filter (make: Rankem). The filtrate was used as sample solution.

\section{Method Validation}

The proposed method was validated as per ICH guidelines [24].

3.1. System Suitability. System suitability parameters were evaluated to verify the system performance. System precision was determined on six replicate injections of standard preparations. All the important characteristics, including the relative standard deviation, peak tailing, and theoretical plate number, were measured. Resolution between impurities was measured by injecting system suitability solution. All these system suitability parameters covered the system, method, and column performance.

3.2. Specificity. Stress studies were performed at an initial concentration of $24000 \mu \mathrm{g} \mathrm{mL}^{-1}$ of GN and $1200 \mu \mathrm{g} \mathrm{mL}^{-1}$ of $\mathrm{DN}$ in active pharmaceutical ingredients (API) and formulated sample to provide the stability-indicating property and specificity of the proposed method. Intentional degradation 
TABLE 1: Structures of Guaifenesin and Dextromethorphan.

Molecule name

was attempted by the stress conditions of exposure to photolytic stress (1.2 million lux hours followed by 200 Watt hours $\mathrm{m}^{-2}$ ), heat (exposed at $105^{\circ} \mathrm{C}$ for $15 \mathrm{~h}$ ), acid $(0.5 \mathrm{~N} \mathrm{HCl}$ for 2 hours at $\left.60^{\circ} \mathrm{C}\right)$, base $\left(0.5 \mathrm{~N} \mathrm{NaOH}\right.$ for 2 hours at $\left.60^{\circ} \mathrm{C}\right)$, oxidation $\left(10 \%\right.$ peroxide for $30 \mathrm{~min}$ at $60^{\circ} \mathrm{C}$ ), water (refluxed for 12 hours at $60^{\circ} \mathrm{C}$ ), and humidity (exposed to $90 \% \mathrm{RH}$ for 7 days).

3.3. Precision. The precision of the determination of the impurities was checked by injecting six individual preparations of $(24000 \mu \mathrm{g} / \mathrm{mL}$ of $\mathrm{GN}$ and $1200 \mu \mathrm{g} / \mathrm{mL}$ of $\mathrm{DN})$ test preparation spiked with $48 \mu \mathrm{g} \mathrm{mL}^{-1}$ of $\mathrm{GN}$ impurities and $2.4 \mu \mathrm{g} \mathrm{mL}^{-1}$ of DN impurities $(0.2 \%$ of the target test concentration) and calculating the $\%$ RSD of $\%$ impurity for each compound. The intermediate precision of the method was also evaluated using different analysts and a different instrument in the same laboratory.

3.4. Limits of Detection (LOD) and Quantification (LOQ). LOD and LOQ for all impurities including GN and DN were determined at a signal-to-noise ratio of $3: 1$ and $10: 1$, respectively, by injecting a series of dilute solutions with known concentrations. Precision study was also carried out at LOQ level by injecting six individual preparations of impurities and \% RSD was calculated.

3.5. Linearity. Linearity test solutions for the method were prepared by diluting stock solution to the required concentrations. The solutions were prepared at six concentration levels from LOQ to the target test concentration. The peak area versus concentration in $\mu \mathrm{g} \mathrm{mL}^{-1}$ data was subjected to leastsquares linear regression analysis.

3.6. Accuracy. Accuracy of the method was evaluated by using concentration levels LOQ, $0.1 \%, 0.2 \%, 0.4 \%, 0.8 \%$, and $1.0 \%$ on $\mathrm{GN}+\mathrm{DN}$ tablets. Six preparations were performed at LOQ and $1.0 \%$ level and three preparations were performed at different levels. Standard addition and recovery experiments were conducted on real sample to determine accuracy of the related substance method. The percentages of recoveries for all impurities, GN, and DN were calculated.

3.7. Robustness. To determine the robustness of the developed method, experimental conditions were deliberately changed and the resolution between GN, DN, and their impurities, tailing factor, and theoretical plates of GN and DN peaks were evaluated. Also relative retention times for all the impurities and column pressure throughout the run were monitored.

To study the effect of the flow rate on the developed method, it was changed from $0.8 \mathrm{~mL} \mathrm{~min}^{-1}$ to 0.6 and $1.0 \mathrm{~mL} \mathrm{~min}^{-1}$. The effect of column temperature on the developed method was studied at 45 and $55^{\circ} \mathrm{C}$ (instead of $50^{\circ} \mathrm{C}$ ). The effect of $\mathrm{pH}$ was studied by varying $\pm 0.2 \mathrm{pH}$ units (i.e., 2.8 and 3.2) and the mobile phase composition was changed $\pm 10 \%$ from the initial composition. In all the above varied conditions, the component of the mobile phase was held constant.

3.8. Stability in Solution and in the Mobile Phase. GN and DN spiked samples (impurities spiked at $0.2 \%$ of the target test concentration, i.e., $48 \mu \mathrm{g} \mathrm{mL}^{-1}$ of $\mathrm{GN}$ impurities and $2.4 \mu \mathrm{g} \mathrm{mL}^{-1}$ of $\mathrm{DN}$ impurities) were prepared in the diluent leaving the test solutions at room temperature. The spiked samples were injected at 0,24 , and $48 \mathrm{hrs}$ time intervals. The impurity content was calculated, and the consistency in the $\%$ area of the principal peak at each interval was checked. The prepared mobile phase was kept constant during the study period. The mobile phase study was demonstrated by injecting the freshly prepared sample solution at different time intervals ( $0-2$ days).

\section{Results and Discussion}

4.1. Optimization of Chromatographic Conditions. The main criterion was developing an RP-HPLC method for the simultaneous determination of impurities in GN and DN pharmaceutical dosage form in a single run, with emphasis 
TABle 2: (a) Structures of Guaifenesin impurities. (b) Structures of Dextromethorphan impurities.

(a)

Impurity name

(b)

\begin{tabular}{lcl}
\hline Impurity name & Chemical name & Chemical structure \\
Impurity A (degradant) & Ent-3-methoxymorphinan
\end{tabular}

Impurity B (degradant)

Ent-17-methylmorphinan-3-ol

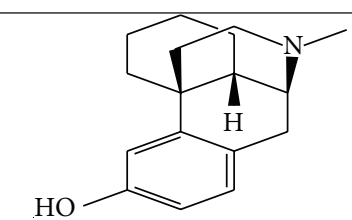

Impurity C (degradant)

Ent-3-methoxy-17-methylmorphinan-10-one

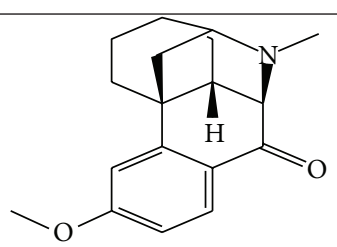

N-Oxide (degradant) 3-Methoxy- $\mathrm{N}$-methylmorphinan $\mathrm{N}$-oxide

N-Formyl Morphine (NFM) (process related impurity)
3-Methoxy-6,7,8,8a,9,10-hexahydro-5H-9,4b(epiminoethano)phenanthrene-11-carbaldehyde<smiles>COc1ccc2c(c1)C13CCCCC1CN(C=O)C3C2</smiles> 


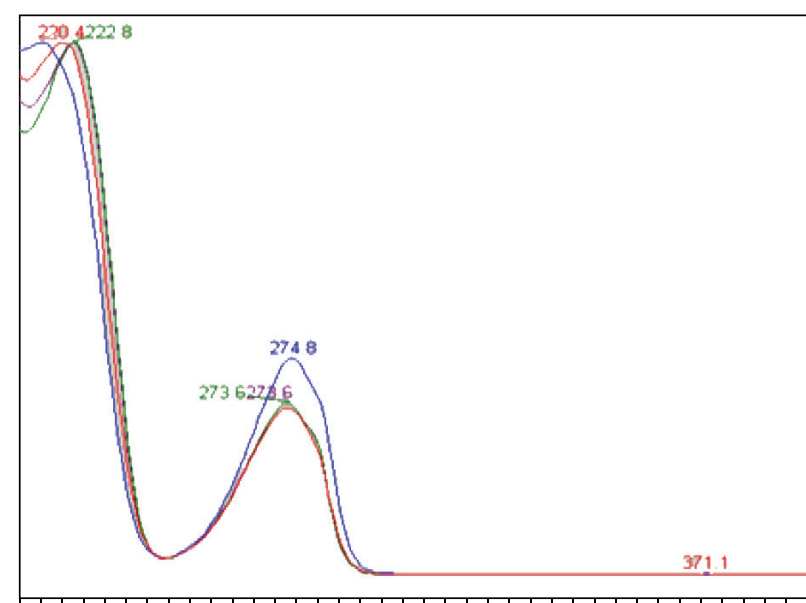

220.00240 .00260 .00280 .00300 .00320 .00340 .00360 .00380 .00 $(\mathrm{nm})$

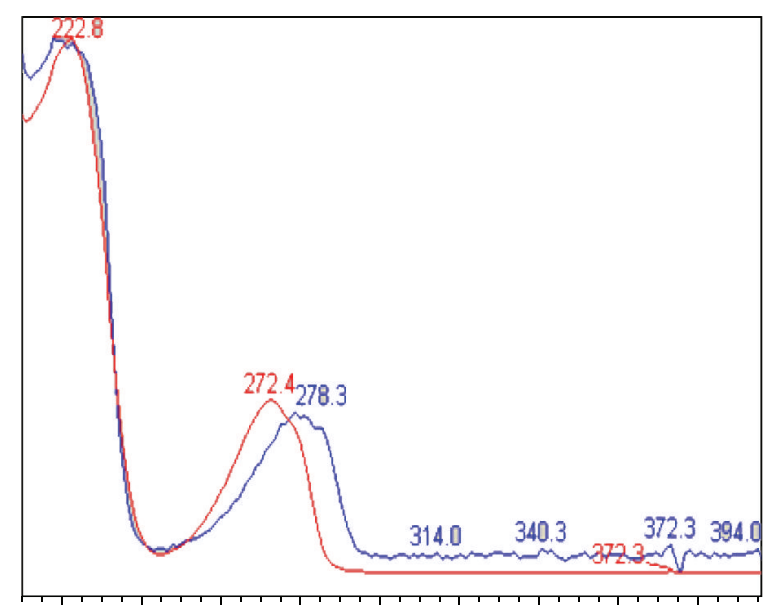

220.00240 .00260 .00280 .00300 .00320 .00340 .00360 .00380 .00

$(\mathrm{nm})$

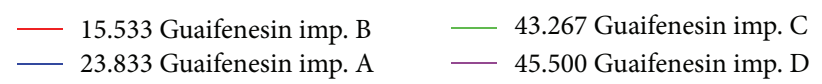

(a) (b)

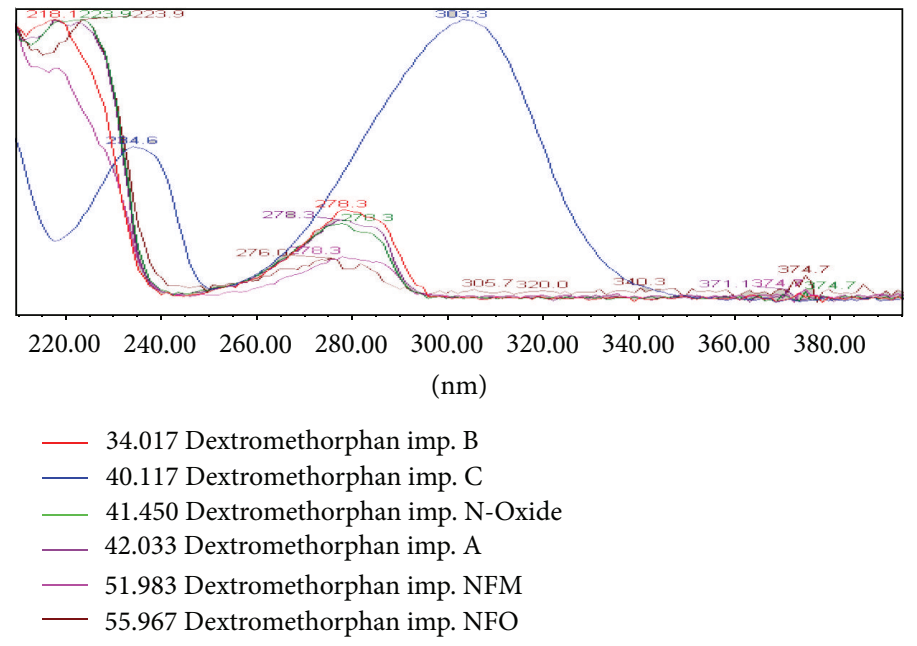

(c)

FIGURE 1: Spectra of GN, DN, and their impurities.

on the method being accurate, reproducible, robust, stabilityindicating, linear, free of interference from other formulation excipients, and convenient enough for routine use in quality control laboratories.

Individual stock solutions of GN, DN, and their impurities were injected and the spectra were checked of each component (Figure 1). From the spectra all the impurities were having absorbance maximum at about 224 . Hence $224 \mathrm{~nm}$ was selected for the estimation of GN and DN impurities.

A spiked solution of impurities $\left(48 \mu \mathrm{g} \mathrm{mL}^{-1}\right.$ of $\mathrm{GN}$ impurities and $2.4 \mu \mathrm{g} \mathrm{mL}^{-1}$ of DN impurities), $\mathrm{GN}+\mathrm{DN}$ $\left(24000 \mu \mathrm{g} \mathrm{mL}^{-1}+1200 \mu \mathrm{g} \mathrm{mL}^{-1}\right)$, and placebo peaks were subjected to separation by RP-HPLC. Initially, the separation was tried with the existing methods (USP, Pharma Europe and the literature method) [27-29]. It was observed that placebo peaks and GN impurity peaks were merging with each other and two DN known impurities (NFM and NFO) were not eluting in DN API Pharma Europe method. In USP and Pharma Europe GN API method, DN impurities were not separated from DN peak and two DN known impurities were eluting at longer retention with broad peak shapes. In case of the literature method [29] DN impurities were not separated from DN peak and two DN known impurities were eluting at longer retention times with better peak shapes.

Method development was initiated by changing different gradient programmes, different $\mathrm{pH}$ values of the mobile phase buffer, different phosphate buffers, and different columns with the literature method [29]. Sharp peak shapes were observed with Sunfire column and sodium dihydrogen phosphate monohydrate buffer at $\mathrm{pH} 3.0$, but separation was not up to the mark for DN, DN-N-oxide, and DN-impurity C. Sharp peak shapes were due to the properties of the Sunfire column (high mass loading capability, excellent low $\mathrm{pH}$ 


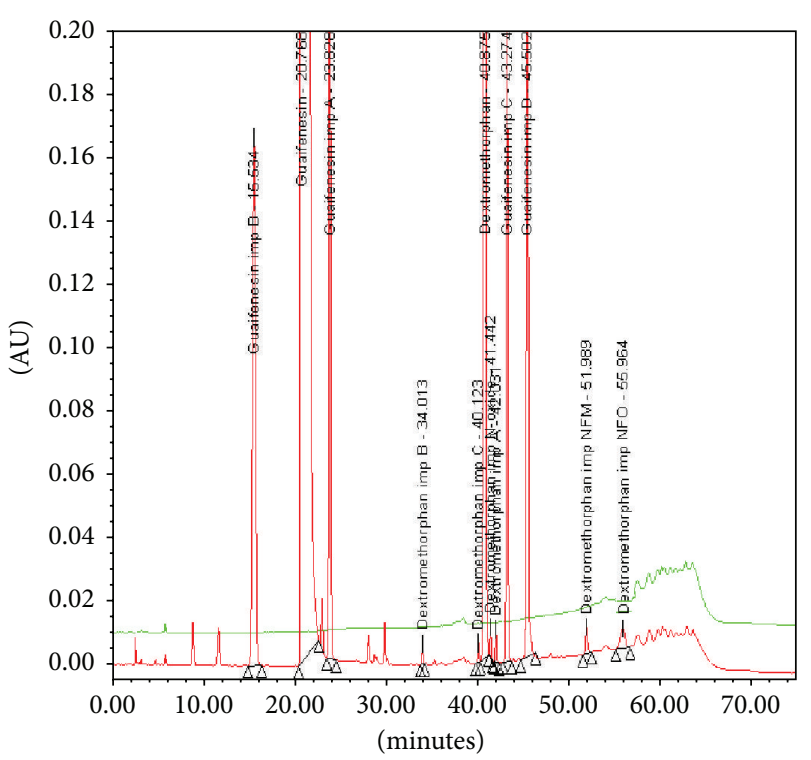

FIGURE 2: Overlaid chromatogram of blank and system suitability preparation.

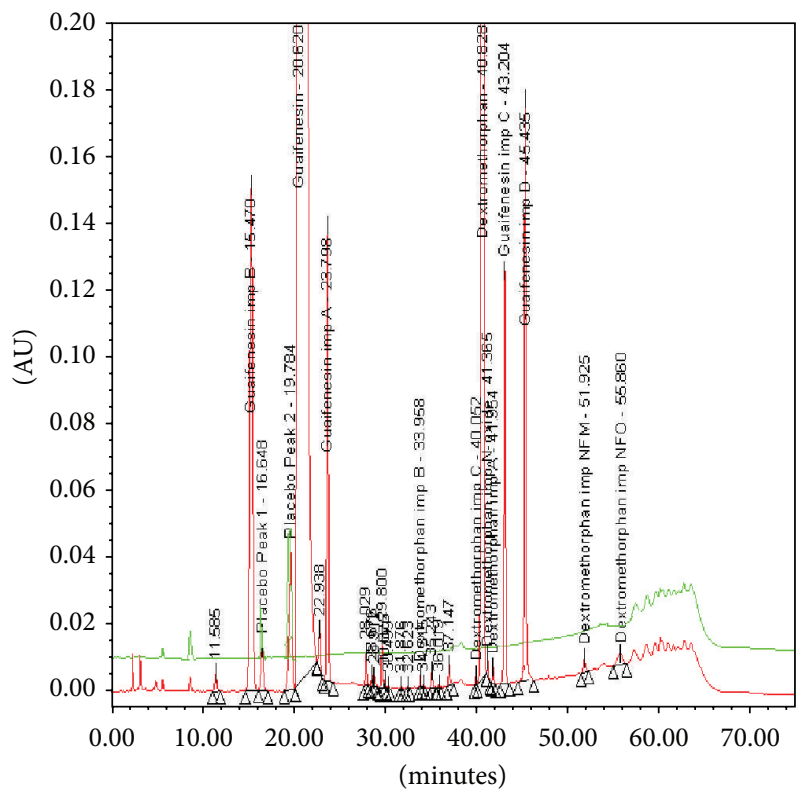

Figure 3: Overlaid chromatogram of placebo and spiked test preparation.

stability, superior peak shapes, and high efficiency). Since we were using a very high concentration of GN $\left(24000 \mu \mathrm{g} \mathrm{m}^{-1}\right)$, it was decided to use Sunfire column for further development trails by using ion pair reagent in the mobile phase for better separation between DN, DN-Impurity A, and DN-Impurity B. Separation was achieved between all the pairs of peaks but peak shapes of DN-NFM Impurity and DN-NFO Impurity are not sharp. Acetonitrile was added in the mobile phase in addition to methanol to get sharp peaks.

The chromatographic separation was achieved by a reversed phase Sunfire, C18, $250 \times 4.6 \mathrm{~mm}, 5 \mu \mathrm{m}$ particle size column operated at $50^{\circ} \mathrm{C}$ with gradient elution at

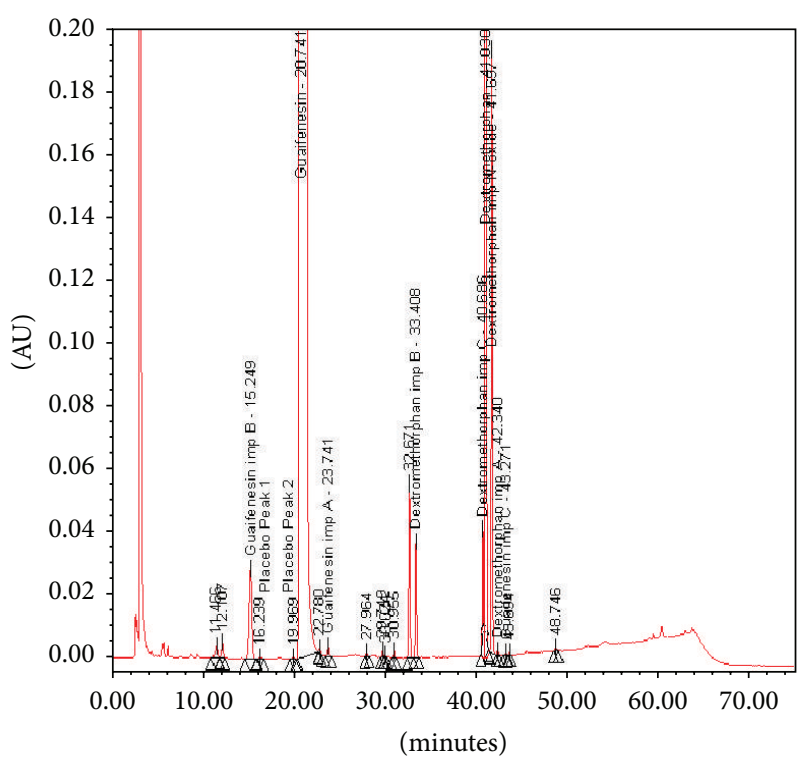

FIGURE 4: Typical chromatogram of peroxide stressed sample.

$0.8 \mathrm{~mL} \mathrm{~min}^{-1}$ using a mobile phase buffer as a mixture of $0.01 \mathrm{M}$ sodium dihydrogen phosphate monohydrate and $0.0046 \mathrm{M}$ 1-octane sulfonic acid sodium salt monohydrate of $\mathrm{pH} 3.0$ ( $\mathrm{pH}$ adjusted with diluted orthophosphoric acid), UV absorbance at $224 \mathrm{~nm}$, and injection volume $20 \mu \mathrm{L}$. The mobile phase A consisted of $\mathrm{pH} 3.0$ buffer and acetonitrile $(90: 10 \mathrm{v} / \mathrm{v})$; mobile phase B consisted of $\mathrm{pH} 3.0$ buffer, acetonitrile, and methanol $(10: 10: 80 \mathrm{v} / \mathrm{v} / \mathrm{v})$. The LC gradient program was set as: time $(\mathrm{min}) / \%$ mobile phase B: $0.01 / 15$, $15 / 5,20 / 30,30 / 50,60 / 85,65 / 15$, and 75/15. All the impurities were well separated with a resolution greater than 2. No chromatographic interference due to the blank (diluent) and other excipients (placebo) at the retention time of GN, $\mathrm{DN}$, and their impurities was observed. The typical overlay chromatogram of blank and system suitability solution and spiked test is shown in Figures 2 and 3.

4.2. Method Validation. After the development of the method it was subject to method validation as per ICH guidelines [24]. The method was validated to demonstrate that it is suitable for its intended purpose by the standard procedure to evaluate adequate validation characteristics (system suitability, specificity, accuracy, precision, linearity, robustness, ruggedness, solution stability, LOD, and LOQ and stabilityindicating capability).

4.2.1. System Suitability. The percentage relative standard deviation (RSD) of area from six replicate injections was below $5.0 \%$ (diluted standard solution, $48 \mu \mathrm{g} \mathrm{mL}^{-1}$ of GN and $2.4 \mu \mathrm{g} \mathrm{mL}^{-1}$ of DN). Low values of RSD for replicate injections indicate that the system is precise. The results of other system suitability parameters such as resolution, peak tailing, and theoretical plates are presented in Table 3. As seen from this data, the acceptable system suitability parameters would be as follows: the relative standard deviation of 


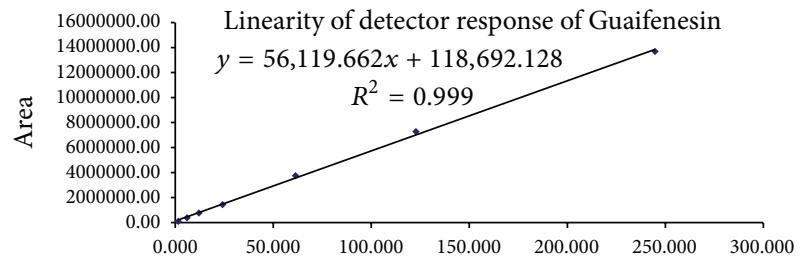

(a)

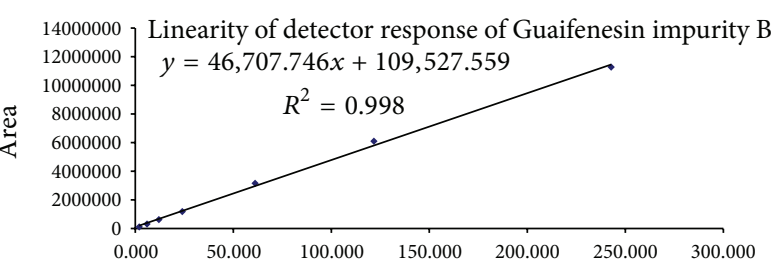

(c)

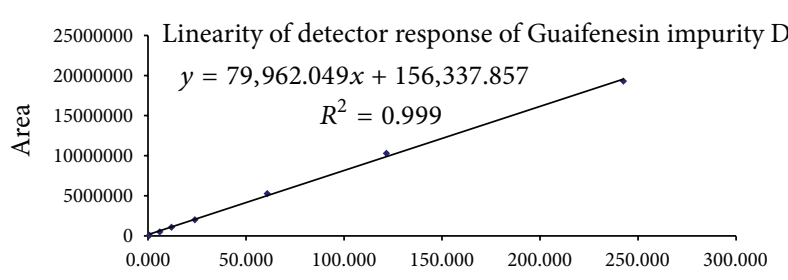

(e)

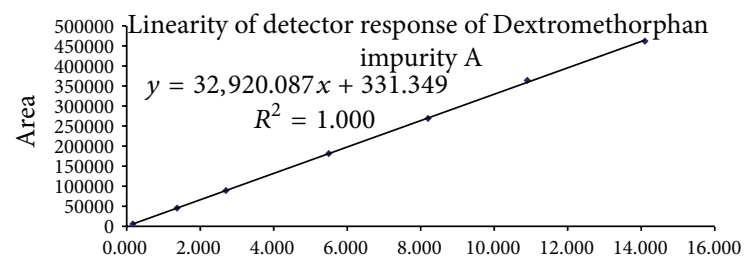

(g)

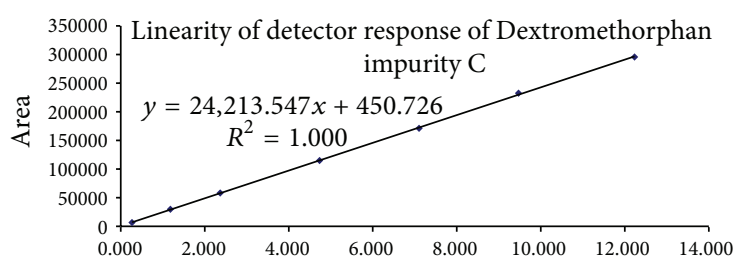

(i)

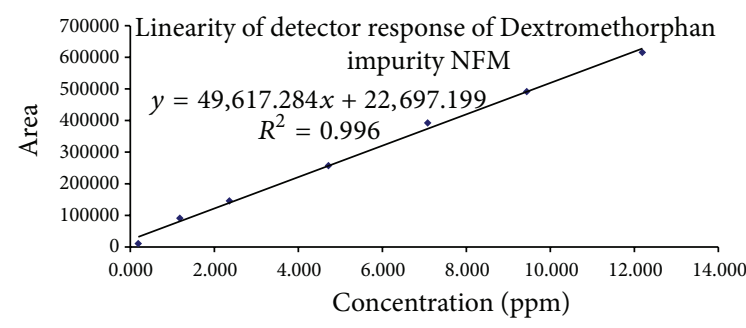

(k)

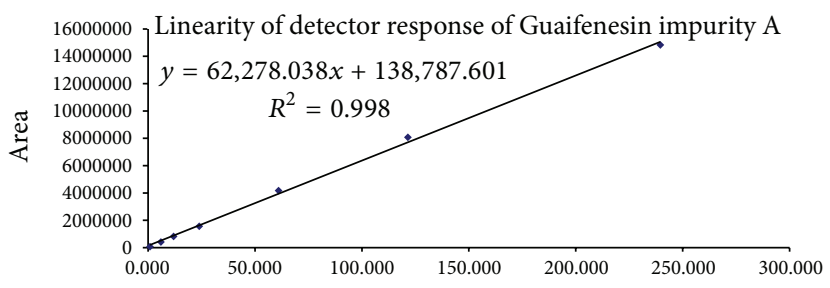

(b)

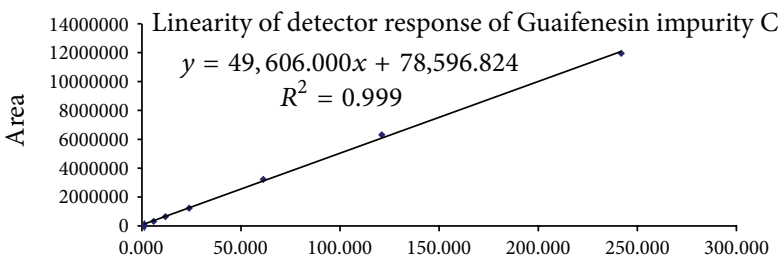

(d)

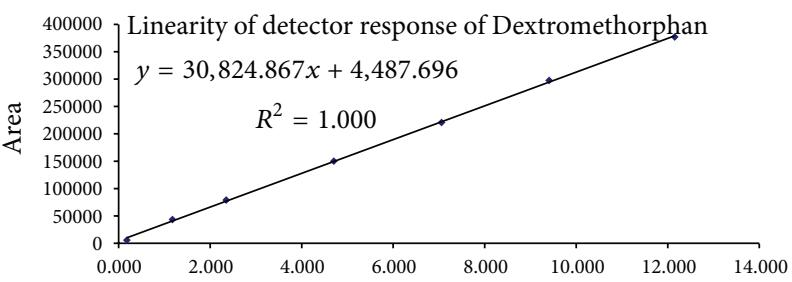

(f)

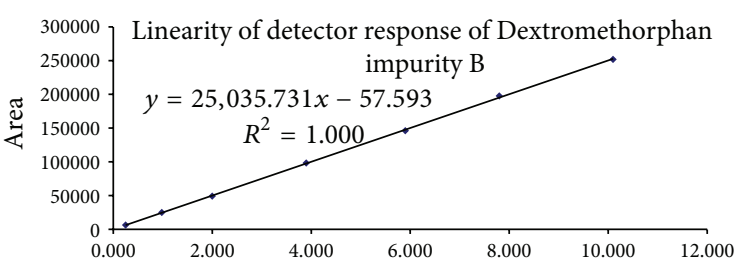

(h)

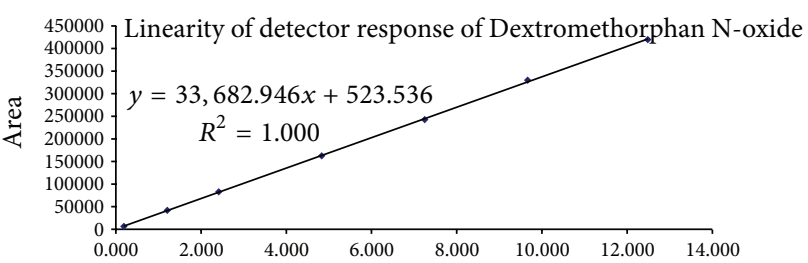

(j)

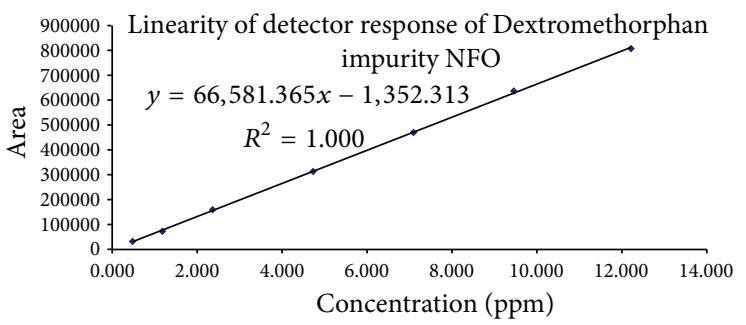

(1)

FIGURE 5: (a) Linearity graph of Guaifenesin. (b) Linearity graph of Guaifenesin impurity A. (c) Linearity graph of Guaifenesin impurity B. (d) Linearity graph of Guaifenesin impurity C. (e) Linearity graph of Guaifenesin impurity D. (f) Linearity graph of Dextromethorphan. (g) Linearity graph of Dextromethorphan impurity A. (h) Linearity graph of Dextromethorphan impurity B. (i) Linearity graph of Dextromethorphan impurity C. (j) Linearity graph of Dextromethorphan N-oxide. (k) Linearity graph of Dextromethorphan impurity NFM.

(l) Linearity graph of Dextromethorphan impurity NFO. 
TABLE 3: System suitability results.

\begin{tabular}{|c|c|c|c|c|c|c|c|c|}
\hline \multirow{2}{*}{ Parameter } & \multicolumn{2}{|c|}{$\% \mathrm{RSD}^{*}$ of standard } & \multicolumn{2}{|c|}{ Theoretical plates ${ }^{*}$} & \multicolumn{2}{|c|}{ Tailing factor ${ }^{*}$} & \multirow{2}{*}{ Resolution 1} & \multirow{2}{*}{ Resolution 2} \\
\hline & $\mathrm{GN}$ & $\mathrm{DN}$ & GN & $\mathrm{DN}$ & GN & $\mathrm{DN}$ & & \\
\hline As such method & 0.5 & 0.7 & 45320 & 498659 & 1.0 & 1.0 & 2.7 & 2.3 \\
\hline At $0.6 \mathrm{~mL} / \mathrm{min}$ flow rate & 1.2 & 0.6 & 41091 & 495497 & 1.0 & 1.0 & 2.9 & 2.5 \\
\hline At $1.0 \mathrm{~mL} / \mathrm{min}$ flow rate & 0.9 & 0.4 & 45828 & 515551 & 1.0 & 1.0 & 2.5 & 2.2 \\
\hline At $50^{\circ} \mathrm{C}$ column temperature & 1.5 & 0.8 & 45321 & 508966 & 1.0 & 1.0 & 2.6 & 2.3 \\
\hline At $60^{\circ} \mathrm{C}$ column temperature & 2.1 & 2.3 & 40929 & 515807 & 1.0 & 1.0 & 2.9 & 2.6 \\
\hline At pH 2.8 (buffer pH) & 1.1 & 0.5 & 43970 & 463987 & 1.0 & 1.0 & 2.4 & 2.3 \\
\hline At pH 3.2 (buffer $\mathrm{pH}$ ) & 0.7 & 1.5 & 44619 & 532891 & 1.0 & 1.0 & 2.6 & 2.7 \\
\hline
\end{tabular}

${ }^{*}$ Average of six replicate standard injections.

TABle 4: (a) Forced degradation data for Guaifenesin. (b) Forced degradation data for Dextromethorphan.

(a)

\begin{tabular}{lcccc}
\hline Degradation conditions & \multicolumn{3}{c}{ Guaifenesin } \\
& \% degraded & Purity angle & Purity threshold & Mass balance (\%) \\
\hline Photo. stress $(1.2$ million lux hours followed by 200 Watt hours) & 0.06 & 3.585 & 4.142 & 100.2 \\
Exposed to humidity at $25^{\circ} \mathrm{C}$ and $90 \% \mathrm{RH}$ for about 7 days & 0.07 & 3.881 & 4.241 & 99.8 \\
Refluxed with purified water for about 12 hours at $60^{\circ} \mathrm{C}$ & 0.05 & 3.285 & 3.845 & 98.6 \\
Refluxed with $0.5 \mathrm{~N} \mathrm{HCL}$ solution for about 2 hours at $60^{\circ} \mathrm{C}$ & 0.10 & 5.293 & 7.073 & 99.2 \\
Refluxed with $0.5 \mathrm{~N} \mathrm{NaOH}$ solution for about 2 hours at $60^{\circ} \mathrm{C}$ & 0.06 & 3.067 & 3.489 & 98.9 \\
Refluxed with $10 \% \mathrm{H}_{2} \mathrm{O}_{2}$ solution for about 30 min at $60^{\circ} \mathrm{C}$ & 0.13 & 2.755 & 3.607 & 98.3 \\
Exposed to dry heat for about 15 hours at $105^{\circ} \mathrm{C}$ & 0.07 & 3.346 & 4.331 & 99.4 \\
\hline
\end{tabular}

(b)

\begin{tabular}{lcccc}
\hline \multirow{2}{*}{ Degradation conditions } & \multicolumn{3}{c}{ Dextromethorphan } \\
& \% degraded & Purity angle & Purity threshold & Mass balance (\%) \\
\hline Photo. stress (1.2 Million lux hours followed by 200 Watt hours) & 0.01 & 0.115 & 0.242 & 99.8 \\
Exposed to humidity at $25^{\circ} \mathrm{C}$ and $90 \% \mathrm{RH}$ for about 7 days & 0.01 & 0.124 & 0.261 & 99.5 \\
Refluxed with purified water for about 12 hours at $60^{\circ} \mathrm{C}$ & 0.01 & 0.101 & 0.261 & 98.9 \\
Refluxed with $0.5 \mathrm{~N} \mathrm{HCL}$ solution for about 2 hours at $60^{\circ} \mathrm{C}$ & 0.02 & 0.154 & 0.262 & 98.1 \\
Refluxed with $0.5 \mathrm{~N} \mathrm{NaOH}$ solution for about 2 hours at $60^{\circ} \mathrm{C}$ & 0.01 & 0.103 & 0.256 & 99.2 \\
Refluxed with $10 \% \mathrm{H}_{2} \mathrm{O}_{2}$ solution for about 30 min at $60^{\circ} \mathrm{C}$ & 1.05 & 0.102 & 0.250 & 99.7 \\
Exposed to dry heat for about 15 hours at $105^{\circ} \mathrm{C}$ & 0.01 & 0.099 & 0.261 & 98.7 \\
\hline
\end{tabular}

TABLE 5: Results of precision.

\begin{tabular}{lcccccccc}
\hline Compound & Prep-1 & Prep-1 & Prep-3 & Prep-4 & Prep-5 & Prep-6 & Avg & \% RSD \\
\hline GN-Impurity A & 0.198 & 0.201 & 0.189 & 0.213 & 0.205 & 0.209 & 0.203 & 4.2 \\
GN-Impurity B & 0.209 & 0.195 & 0.192 & 0.201 & 0.206 & 0.194 & 0.200 & 3.5 \\
GN-Impurity C & 0.189 & 0.195 & 0.186 & 0.192 & 0.198 & 0.184 & 0.191 & 2.8 \\
GN-Impurity D & 0.208 & 0.190 & 0.192 & 0.193 & 0.188 & 0.186 & 0.193 & 4.1 \\
DN-Impurity A & 0.215 & 0.214 & 0.215 & 0.209 & 0.212 & 0.205 & 0.212 & 1.9 \\
DN-Impurity B & 0.204 & 0.200 & 0.202 & 0.203 & 0.205 & 0.191 & 0.201 & 2.5 \\
DN-Impurity C & 0.195 & 0.186 & 0.198 & 0.199 & 0.184 & 0.194 & 0.193 \\
DN-N-oxide & 0.216 & 0.214 & 0.218 & 0.219 & 0.211 & 0.210 & 0.215 \\
DN-NFM Impurity & 0.216 & 0.218 & 0.215 & 0.215 & 0.216 & 0.212 & 0.215 \\
DN-NFO Impurity & 0.198 & 0.195 & 0.213 & 0.192 & 0.214 & 0.215 & 0.205 \\
GN & 0.203 & 0.212 & 0.204 & 0.206 & 0.205 & 0.210 & 0.2 \\
DN & 0.182 & 0.189 & 0.194 & 0.188 & 0.187 & 0.201 & 0.19 \\
\hline
\end{tabular}


TABLE 6: Results of intermediate precision.

\begin{tabular}{lcccccccc}
\hline Compound & Prep-1 & Prep-1 & Prep-3 & Prep-4 & Prep-5 & Prep-6 & Avg. & \% RSD \\
\hline GN-Impurity A & 0.191 & 0.204 & 0.201 & 0.199 & 0.210 & 0.212 & 0.203 & 3.8 \\
GN-Impurity B & 0.212 & 0.204 & 0.210 & 0.209 & 0.211 & 0.204 & 0.208 & 1.7 \\
GN-Impurity C & 0.192 & 0.198 & 0.191 & 0.194 & 0.202 & 0.209 & 0.198 & 3.5 \\
GN-Impurity D & 0.185 & 0.192 & 0.191 & 0.194 & 0.193 & 0.192 & 0.192 & 1.5 \\
DN-Impurity A & 0.202 & 0.202 & 0.203 & 0.202 & 0.202 & 0.204 & 0.203 & 0.4 \\
DN-Impurity B & 0.191 & 0.188 & 0.204 & 0.209 & 0.189 & 0.202 & 0.197 & 4.5 \\
DN-Impurity C & 0.183 & 0.189 & 0.191 & 0.186 & 0.205 & 0.206 & 0.193 & 5.1 \\
DN-N-oxide & 0.197 & 0.210 & 0.213 & 0.202 & 0.198 & 0.212 & 0.205 \\
DN-NFM Impurity & 0.183 & 0.187 & 0.179 & 0.184 & 0.185 & 0.188 & 0.184 & 3.5 \\
DN-NFO Impurity & 0.206 & 0.197 & 0.209 & 0.212 & 0.194 & 0.208 & 0.204 & 3.7 \\
GN & 0.199 & 0.205 & 0.201 & 0.204 & 0.207 & 0.208 & 0.204 \\
DN & 0.187 & 0.185 & 0.192 & 0.186 & 0.194 & 0.191 & 0.189 & 1.7 \\
\hline
\end{tabular}

TABLE 7: LOD, LOQ, and precision data.

\begin{tabular}{|c|c|c|c|c|c|}
\hline \multirow{2}{*}{ Compound } & \multirow{2}{*}{ LOD (\%) } & \multirow{2}{*}{ LOQ (\%) } & \multicolumn{2}{|c|}{$\mathrm{S} / \mathrm{N}$ ratio } & \multirow{2}{*}{ \% RSD at LOQ Level precision } \\
\hline & & & LOD & LOQ & \\
\hline GN-Impurity A & 0.004 & 0.001 & 2.7 & 9.5 & 4.2 \\
\hline GN-Impurity B & 0.008 & 0.002 & 2.9 & 9.8 & 2.5 \\
\hline GN-Impurity C & 0.005 & 0.002 & 3.0 & 9.8 & 3.1 \\
\hline GN-Impurity D & 0.003 & 0.001 & 2.9 & 9.7 & 2.5 \\
\hline DN-Impurity A & 0.014 & 0.004 & 2.8 & 10.1 & 1.1 \\
\hline DN-Impurity B & 0.021 & 0.006 & 2.7 & 10.4 & 3.4 \\
\hline DN-Impurity C & 0.023 & 0.007 & 2.8 & 9.9 & 4.9 \\
\hline DN-N-oxide & 0.016 & 0.005 & 3.1 & 9.8 & 2.2 \\
\hline DN-NFM Impurity & 0.016 & 0.005 & 2.7 & 10.1 & 1.5 \\
\hline DN-NFO Impurity & 0.041 & 0.012 & 2.9 & 10.6 & 4.2 \\
\hline $\mathrm{GN}$ & 0.006 & 0.002 & 3.1 & 9.8 & 2.1 \\
\hline $\mathrm{DN}$ & 0.015 & 0.005 & 2.8 & 9.6 & 2.8 \\
\hline
\end{tabular}

replicate injections is not more than $5.0 \%$, resolution between impurities 2.0, the tailing factor for GN and $\mathrm{DN}$ is not more than 1.5, and the theoretical plates are not less than 5000 .

4.2.2. Specificity. All forced degradation samples were analyzed with the aforementioned HPLC conditions using a PDA detector to monitor the homogeneity and purity of the GN, DN, and their related impurities. Individual impurities, placebo, GN, and DN were verified and proved to be noninterfering with each other thus proving the specificity of the method.

Figure 3 shows that there is no interference at the RT (retention time) of GN, DN, and all known impurities from the other excipients. Degradation was not observed in photolytic stress, humidity, acid hydrolysis, base hydrolysis, water hydrolysis, and thermal stress studies. Significant degradation was observed in oxidative conditions. The typical oxidative stressed chromatogram was shown in Figure 4. It was interesting to note that all the peaks due to degradation were well resolved from the peaks of $\mathrm{GN}, \mathrm{DN}$, and their impurities. Further the peak purity of GN, DN, and their impurities was found to be homogeneous based on the evaluation parameters such as purity angle and purity threshold using Waters Empower Networking Software. The verification of peak purity indicates that there is no interference from degradants, facilitating error-free quantification of GN and DN impurities. Also the mass balance of stressed samples was found to be more than $98 \%$. Thus, the method is considered to be "stability-indicating." The specificity results were shown in Tables 4(a) and 4(b).

4.2.3. Precision. The \% RSD for the individual \% of all impurities in impurities method precision study was within $3.4 \%$. The results obtained in the intermediated precision study for the $\%$ RSD of the individual $\%$ of all impurities were well within $4.1 \%$, conforming high precision of the method. The results are shown in Tables 5 and 6. 
TABLE 8: Accuracy of the method.

\begin{tabular}{|c|c|c|c|c|c|c|}
\hline \multirow{2}{*}{ Compound } & \multicolumn{6}{|c|}{$\%$ Recovery at each level $^{\mathrm{a}}$} \\
\hline & LOQ & $0.1 \%$ & $0.2 \%$ & $0.4 \%$ & $0.8 \%$ & $1.0 \%$ \\
\hline GN-Impurity A & 98.5 & 99.5 & 101.2 & 96.7 & 99.9 & 103.5 \\
\hline GN-Impurity B & 105.6 & 102.7 & 99.7 & 105.1 & 98.5 & 97.5 \\
\hline GN-Impurity C & 102.6 & 105.6 & 101.9 & 106.1 & 103.5 & 102.1 \\
\hline GN-Impurity D & 95.6 & 97.2 & 96.5 & 95.8 & 96.5 & 98.5 \\
\hline DN-Impurity A & 93.5 & 96.5 & 95.2 & 94.2 & 98.5 & 96.7 \\
\hline DN-Impurity B & 98.5 & 96.7 & 99.9 & 98.9 & 97.5 & 96.5 \\
\hline DN-Impurity C & 101.1 & 102.3 & 102.5 & 103.7 & 102.5 & 101.8 \\
\hline DN-N-oxide & 105.6 & 106.5 & 105.1 & 104.5 & 102.9 & 103.7 \\
\hline DN-NFM Impurity & 101.5 & 98.5 & 102.5 & 101.2 & 99.5 & 98.6 \\
\hline DN-NFO Impurity & 107.1 & 105.6 & 106.9 & 105.8 & 106.5 & 105.8 \\
\hline GN & 98.5 & 96.5 & 97.2 & 96.8 & 97.4 & 98.7 \\
\hline $\mathrm{DN}$ & 99.2 & 98.5 & 97.1 & 99.5 & 100.5 & 101.2 \\
\hline
\end{tabular}

${ }^{a}$ Average of six determinations at LOQ level \& $1.0 \%$ level and three determinations at remaining levels.

TABLE 9: Regression statistics.

\begin{tabular}{lccc}
\hline Substance & Linearity range $\left(\mu \mathrm{g} \mathrm{mL} \mathrm{m}^{-1}\right)$ & Correlation coefficient $(R)$ & $Y$-intercept bias in \% \\
\hline GN-Impurity A & 0.93 to 239.61 & 0.999 & 0.9 \\
GN-Impurity B & 2.01 to 242.78 & 0.999 & 1.0 \\
GN-Impurity C & 1.26 to 241.92 & 0.999 & 0.7 \\
GN-Impurity D & 0.79 to 242.55 & 1.000 & 0.8 \\
DN-Impurity A & 0.17 to 14.10 & 1.000 & 0.4 \\
DN-Impurity B & 0.25 to 10.10 & 1.000 & 0.1 \\
DN-Impurity C & 0.27 to 12.23 & 1.000 & 0.8 \\
DN-N-oxide & 0.19 to 12.49 & 0.998 & 0.6 \\
DN-NFM Impurity & 0.19 to 12.19 & 1.000 & 1.5 \\
DN-NFO Impurity & 0.48 to 12.22 & 0.999 & 0.9 \\
GN & 1.53 to 244.78 & 1.000 & 1.6 \\
DN & 0.18 to 12.15 & & 0.1 \\
\hline
\end{tabular}

TABLE 10: Results of robustness study.

\begin{tabular}{|c|c|c|c|c|c|c|c|c|}
\hline \multirow[b]{2}{*}{ S. no. } & \multirow[b]{2}{*}{ Impurity name } & \multicolumn{7}{|c|}{ RRT's of impurities } \\
\hline & & $\begin{array}{l}\text { As such } \\
\text { method }\end{array}$ & $\begin{array}{c}\text { At } \\
0.6 \mathrm{~mL} / \mathrm{min} \\
\text { flow rate }\end{array}$ & $\begin{array}{c}\text { At } \\
1.0 \mathrm{~mL} / \mathrm{min} \\
\text { flow rate }\end{array}$ & $\begin{array}{c}\text { At } 50^{\circ} \mathrm{C} \\
\text { column } \\
\text { temperature }\end{array}$ & $\begin{array}{c}\text { At } 60^{\circ} \mathrm{C} \\
\text { column } \\
\text { temperature }\end{array}$ & $\begin{array}{c}\text { At pH } 2.8 \\
\text { (buffer pH) }\end{array}$ & $\begin{array}{c}\text { At pH } 3.2 \\
\text { (buffer pH) }\end{array}$ \\
\hline 1 & GN-Impurity A & 0.74 & 0.76 & 0.73 & 0.72 & 0.71 & 0.74 & 0.73 \\
\hline 2 & GN-Impurity B & 1.12 & 1.11 & 1.13 & 1.11 & 1.10 & 1.12 & 1.13 \\
\hline 3 & GN-Impurity C & 2.04 & 2.06 & 2.05 & 2.05 & 2.02 & 2.04 & 2.05 \\
\hline 4 & GN-Impurity D & 2.14 & 2.12 & 2.15 & 2.13 & 2.11 & 2.13 & 2.14 \\
\hline 5 & DN-Impurity B & 0.83 & 0.82 & 0.81 & 0.82 & 0.82 & 0.83 & 0.82 \\
\hline 6 & DN-Impurity C & 0.98 & 0.97 & 0.98 & 0.98 & 0.97 & 0.97 & 0.98 \\
\hline 7 & DN-N-oxide & 1.01 & 1.02 & 1.03 & 1.02 & 1.03 & 1.02 & 1.04 \\
\hline 8 & DN-Impurity A & 1.03 & 1.04 & 1.05 & 1.04 & 1.05 & 1.04 & 1.06 \\
\hline 9 & DN-NFM Impurity & 1.28 & 1.31 & 1.30 & 1.31 & 1.29 & 1.28 & 1.19 \\
\hline 10 & DN-NFO Impurity & 1.38 & 1.41 & 1.42 & 1.39 & 1.39 & 1.39 & 1.41 \\
\hline
\end{tabular}

Note: GN known impurities RRTs were calculated against GN main peak, and DN known impurities RRTs were calculated against DN main peak. 
4.2.4. Limit of Detection (LOD) and Limit of Quantification (LOQ). The determined limit of detection, limit of quantification, and precision at LOQ values for GN, DN, and their impurities were reported in Table 7. The RSD for peak areas of $\mathrm{GN}, \mathrm{DN}$, and their related impurities at limit of quantification level was within $10.0 \%$.

4.2.5. Accuracy. The recovery of all the impurities from finished pharmaceutical dosage form ranged from $85.0 \%$ to $115.0 \%$. The summary of $\%$ recovery for individual impurity was mentioned in Table 8.

4.2.6. Linearity. Linear calibration plot for the related substance method was obtained over the calibration ranges tested, that is, LOQ to $1.0 \%$ of the target test concentration. The correlation coefficient obtained was greater than 0.997 for all the components. The slope and y-intercept values were also provided in Table 9, which confirmed good linearity between peak areas and concentration. The linearity graphs were shown in Figure 5(a) to Figure 5(l).

4.2.7. Robustness. No significant effect was observed on system suitability parameters such as resolution, RSD, tailing factor, RRTs of impurities, or the theoretical plates of GN and DN when small but deliberate changes were made to chromatographic conditions. The results were presented in Tables 3 and 10, along with the system suitability parameters of normal conditions. Thus, the method was found to be robust with respect to variability in applied conditions.

4.2.8. Stability in Solution and in the Mobile Phase. No significant changes were observed in the content of impurities during solution stability and mobile phase stability experiments when performed using the impurities method. The solution stability and mobile phase stability experiment data confirms that the sample solution and mobile phases used during the impurity determination were stable for at least $48 \mathrm{~h}$.

\section{Conclusions}

The gradient HPLC method developed for the simultaneous determination of GN and DN impurities in pharmaceutical dosage form was precise, accurate, and specific. The method is validated as per ICH guidelines and found to be specific, precise, linear, accurate, rugged, and robust. The developed method can be used for the stability analysis of GN and DN either individually or in their combination dosage forms.

\section{Acknowledgments}

The authors wish to thank the management of Dr. Reddy's group for supporting this work. The authors wish to acknowledge the formulation development group for providing the samples for their research. They would also like to thank colleagues in bulk manufacturers for providing chemicals and impurity standards for their research work.

\section{References}

[1] http://www.rxlist.com/organidin-nr-drug.htm.

[2] W. Zhang, T. Wang, L. Qin et al., "Neuroprotective effect of dextromethorphan in the MPTP Parkinson's disease model: role of NADPH oxidase," The FASEB Journal, vol. 18, no. 3, pp. 589-591, 2004.

[3] Dextromethorphan, NHTSA.

[4] "Child deaths lead to FDA hearing on cough, cold meds," 2007, http://www.cnn.com/.

[5] B. KuKanich and M. G. Papich, "Plasma profile and pharmacokinetics of dextromethorphan after intravenous and oral administration in healthy dogs," Journal of Veterinary Pharmacology and Therapeutics, vol. 27, no. 5, pp. 337-341, 2004.

[6] "Kids' cough medicine no better than placebo," San Francisco Chronicle, 2004.

[7] I. M. Paul, K. E. Yoder, K. R. Crowell et al., "Effect of dextromethorphan, diphenhydramine, and placebo on nocturnal cough and sleep quality for coughing children and their parents," Pediatrics, vol. 114, no. 1, pp. e85-e90, 2004.

[8] S. Görög, M. Babják, G. Balogh et al., "Drug impurity profiling strategies," Talanta, vol. 44, no. 9, pp. 1517-1526, 1997.

[9] B. B. Sanjay, R. K. Bharati, S. J. Yogini, and A. S. Atul, "Impurity profile: significance in active pharmaceutical ingredient," Eurasian Journal of Analytical Chemistry, vol. 2, pp. 32-53, 2007.

[10] ICH, "Impurities in new drug substances Q3A (R2)," 2006.

[11] ICH, "Impurities in new drug products Q3B (R2)," 2006.

[12] G. Grosa, E. D. Grosso, R. Russo, and G. Allegrone, "Simultaneous, stability indicating, HPLC-DAD determination of guaifenesin and methyl and propyl-parabens in cough syrup," Journal of Pharmaceutical and Biomedical Analysis, vol. 41, no. 3, pp. 798-803, 2006.

[13] M. Senthilraja and P. Giriraj, "Reverse phase hplc method for the simultaneous estimation of terbutanile sulphate, bromhexine $\mathrm{HCl}$ and guaifenesin in cough syrup," Asian Journal of Pharmaceutical and Clinical Research, vol. 4, no. 2, pp. 13-15, 2011.

[14] M. L. Wilcox and J. T. Stewart, "HPLC determination of guaifenesin with selected medications on underivatized silica with an aqueous-organic mobile phase," Journal of Pharmaceutical and Biomedical Analysis, vol. 23, no. 5, pp. 909-916, 2000.

[15] A. Özdemir, H. Aksoy, E. Dinç, D. Bǎleanu, and S. Dermiş, “Determination of guaifenesin and dextromethorphan in a cough syrup by HPLC with fluorometric detection," Revue Roumaine de Chimie, vol. 51, no. 2, pp. 117-122, 2006.

[16] I. Demian, "High-performance liquid chromatography (HPLC) chiral separations of guaifenesin, methocarbamol, and racemorphan," Chirality, vol. 5, no. 4, pp. 238-240, 1993.

[17] S. Süzen, C. Akay, and Ş. Cevheroglu, "Simultaneous determination of guaiphenesin and codeine phosphate in tablets by high-performance liquid chromatography," Farmaco, vol. 54, no. 10, pp. 705-709, 1999.

[18] S. M. Amer, S. S. Abbas, M. A. Shehata, and N. M. Ali, "Simultaneous determination of phenylephrine hydrochloride, guaifenesin, and chlorpheniramine maleate in cough syrup by gradient liquid chromatography," Journal of AOAC International, vol. 91, no. 2, pp. 276-284, 2008.

[19] V. Galli and C. Barbas, "High-performance liquid chromatographic analysis of dextromethorphan, guaifenesin and benzoate in a cough syrup for stability testing," Journal of Chromatography A, vol. 1048, no. 2, pp. 207-211, 2004. 
[20] X. Chen, J. Huang, Z. Kong, and D. Zhong, "Sensitive liquid chromatography-tandem mass spectrometry method for the simultaneous determination of paracetamol and guaifenesin in human plasma," Journal of Chromatography B, vol. 817, no. 2, pp. 263-269, 2005.

[21] R. M. Gudipati, J. E. Wallace, and S. A. Stavchansky, "High performance liquid chromatography determination of guaifenesin in dog plasma," Analytical Letters, vol. 24, pp. 265-274, 1991.

[22] Q.-H. Ge, Z. Zhou, X.-J. Zhi, L.-L. Ma, and C.-G. Ding, "Simultaneous determination of guaifenesin, bromhexine and ambroxol in human plasma by LC-MS/MS and its pharmacokinetic studies," Chinese Pharmaceutical Journal, vol. 44, no. 13, pp. 1025-1028, 2009.

[23] R. Rajagopalan, "Review of regulatory guidance on impurities," Separation Science and Technology, vol. 5, pp. 27-37, 2004.

[24] ICH, Harmonized Tripartite Guideline, Validation of Analytical Procedures: Text and Methodology Q2(R1), 2005.

[25] ICH, "Stability testing of new drug substances and products Q1A (R2)," 2003.

[26] ICH, "Photostability testing of new drug substances and products Q1B,” 1996.

[27] The United States Pharmacopeia, USP35-NF30: 3829-3837.

[28] European Pharmacopeia, 7.0: 1821-1822 \& 2128-2129.

[29] P. Sunil Reddy, K. Sudhakar Babu, N. Kumar, and Y. V. V. Sasi Sekhar, "Development and validation of stability indicating the RP-HPLC method for the estimation of related compounds of guaifenesin in pharmaceutical dosage forms," Pharmaceutical Methods, vol. 2, pp. 229-234, 2011. 

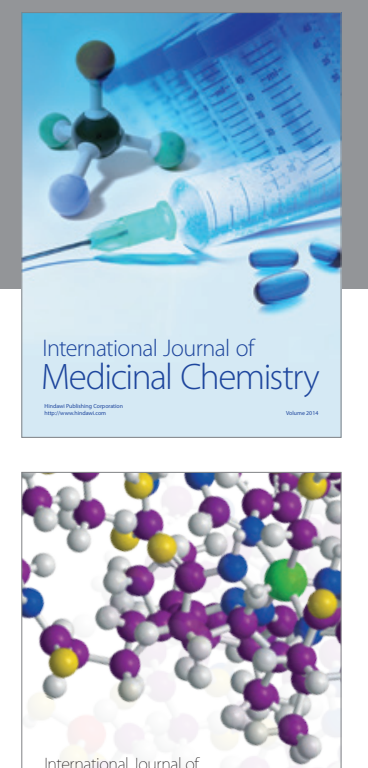

\section{Carbohydrate} Chemistry

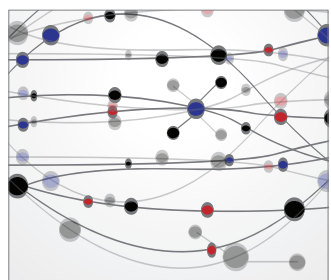

The Scientific World Journal
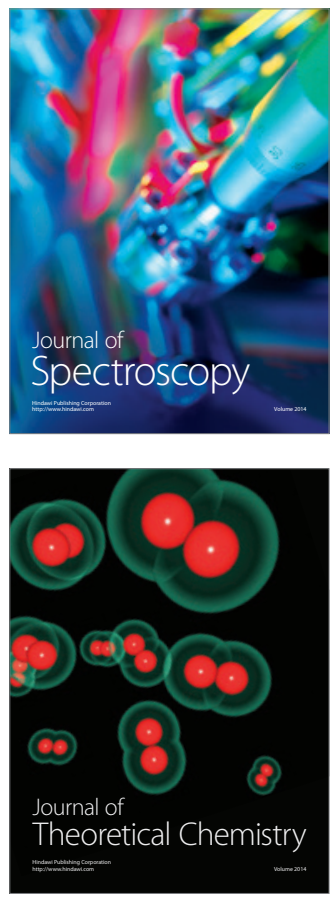
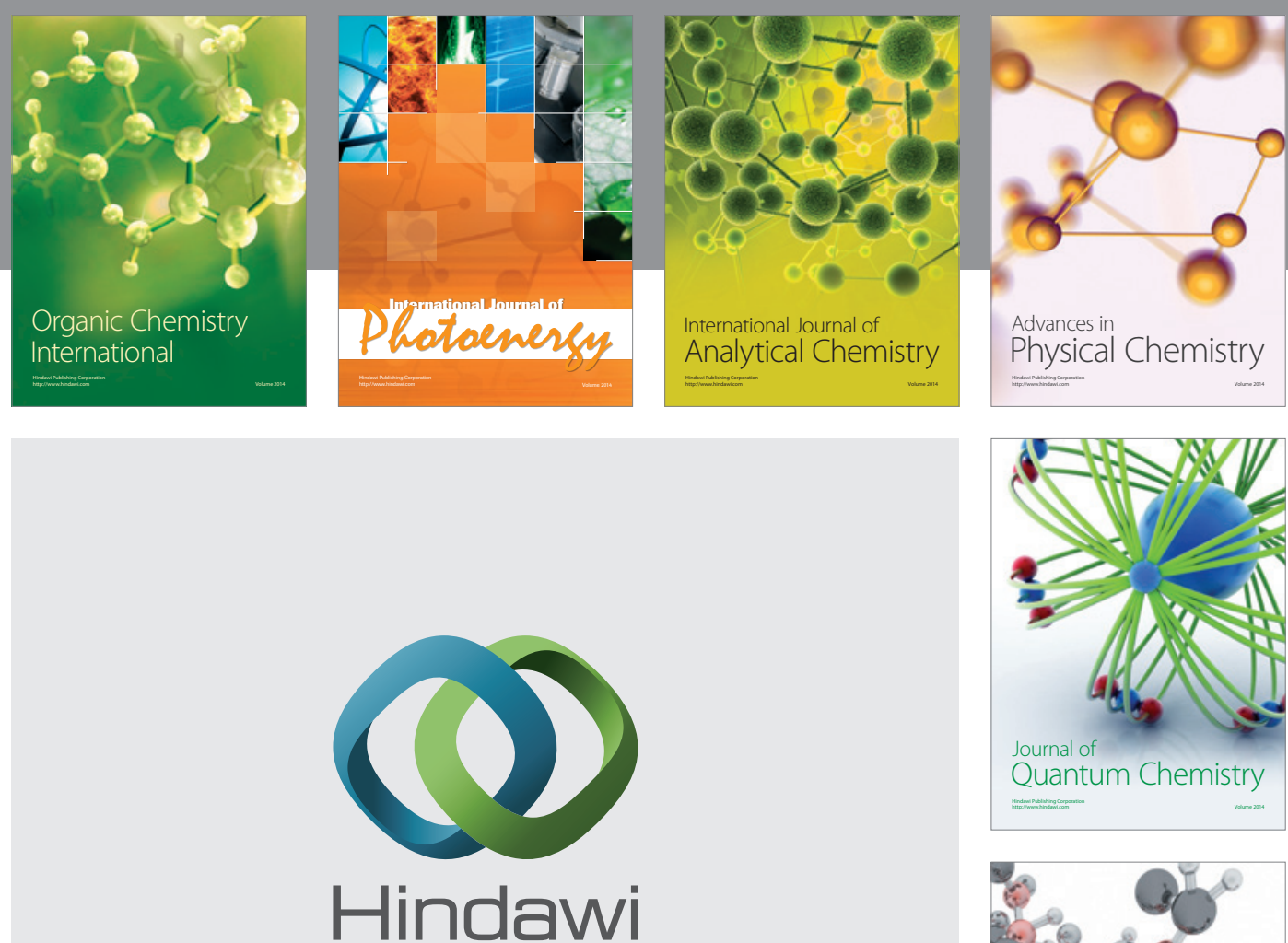

Submit your manuscripts at

http://www.hindawi.com

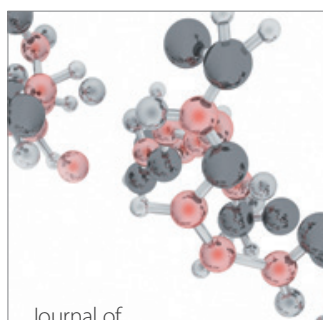

Analytical Methods

in Chemistry

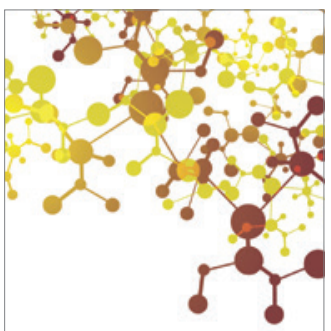

Journal of

Applied Chemistry

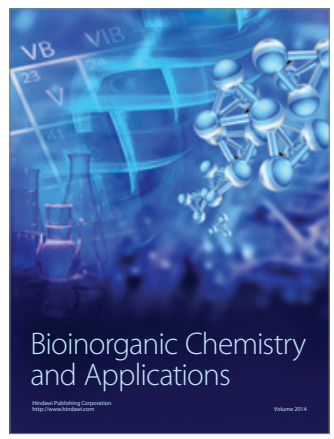

Inorganic Chemistry
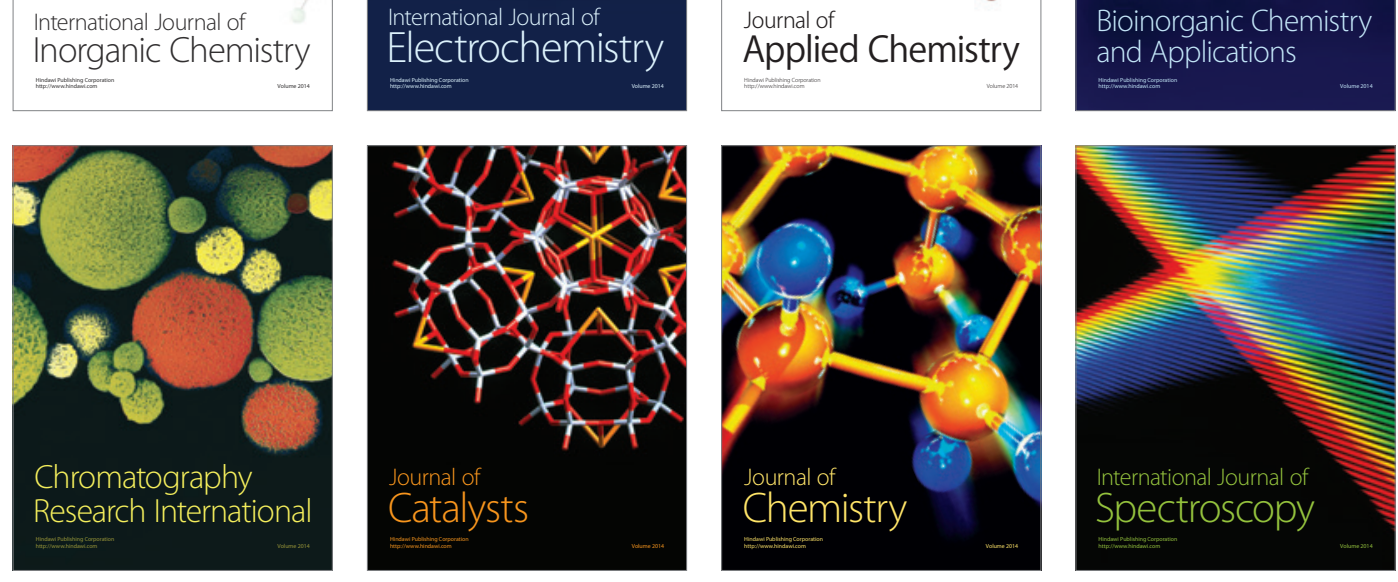